\title{
Fuentes para el estudio del exilio literario catalán en Hispanoamérica
}

\author{
Óscar FernándeZ PoZA y Juan M. RIBERA LLOPIS \\ Departamento de Filología Románica, Filología Eslava y Lingüística General \\ Universidad Complutense de Madrid \\ oskarfp20@hotmail.com y jumriber@filol.ucm.es
}

\section{RESUMEN}

Aproximación histórica al exilio catalán del tiempo de la República, a sus primeros pasos y a su reconducción hacia Hispanoamérica. Presentación de las fuentes de estudio, atendiendo a diferentes niveles informativos, desde las memorias de los exiliados hasta la bibliografía historiográfica existente y a los actuales grupos de investigación centrados en el exilio español y, puntualmente, el catalán. Atención al caso concreto, como muestra de una experiencia individualizada, de Avel·lí Artís Balaguer, escritor catalán exiliado en México, a su activismo cultural y a la continuación de su obra durante su expatriación.

Palabras clave: Historia política y cultural española, literatura catalana contemporánea y exilio, autores catalanes exiliados en Hispanoamérica, fuentes de estudio, Avel·lí Artís Balaguer, vida, obra y documentación.

\section{Sources for the study of Catalonian exile in Hispanic America}

\begin{abstract}
A historical approach to Catalan republican exile, its first steps towars Latin America and its renawal. A presentation of sources of study, taking into account different levels of information, from memoires of the exiles to the existing historiographical literature and current research groups focusing on the Spanish exile and, occasionally, Catalan. Special attention to the case, as evidence of individual experience, of Avel·lí Artís Balaguer, a Catalan writer in exile in Mexico, to his cultural activism and to his continued work during his expatriation.
\end{abstract}

Key words: Spanish political and cultural history, contemporary Catalan literature and exile, Catalan authors in exile in Latin America, study sources, Avel·lí Artís Balaguer, life, work and documentation. 


\section{PREMISAS Y FUENTES GENERALES}

Además de los intelectuales que abandonaron el territorio lingüística y culturalmente catalán entre la crisis prebélica y la propia contienda civil, personalidades en absoluto ajenas al devenir de los exiliados en 1939, se ha de incidir en que el grueso de intelectuales de expresión catalana, junto con sus familias, vivió el primer paso de su éxodo entre los días 24 y 25 de enero de ese año. Se sumaban, de este modo, a la orden del día 22 de aquel mes dictada por Juan Negrín, Presidente del Consejo de Ministros y Ministro de Defensa del Gobierno Republicano, a propósito de la evacuación de Barcelona del aparato administrativo del Gobierno Central, arrastrando al de la Generalitat de Catalunya, con una primera parada y ubicación provisional en Girona. La Conselleria de Cultura de la Generalitat organizó dos grupos de salida y, en el gerundense Mas Perxés de la Agullana y a la espera de la orden de cruzar la frontera hacia la Catalunya Nord, el día 27 de enero, se celebró la última reunión de la Institució de les Lletres Catalanes. En su acta, siempre con el fin de preservar la lengua y la cultura propia, se expresaba el acuerdo de "[...] acollir sota la protecció de la Institució, els escriptors que han volgut seguir-la" (Pessarrodona 2010: 45).

En consonancia con esa propuesta, las autoridades culturales catalanas se movilizaron a favor de los intelectuales. Una primera e inmediata iniciativa, por parte de la mencionada Institució bajo la presidencia de Carles Pi i Sunyer, atendió a la organización de residencias de acogida y al reforzamiento de las relaciones y colaboración con instituciones internacionales como el PEN Club. La creación en octubre de 1939 de la Fundació Ramon Llull en París permitiría la coordinación de la infraestructura en ayuda de los intelectuales y fraguaría las manifestaciones culturales en el exilio. Sobre tal base, la posterior fundación en el año 1940 del Consell Nacional de Catalunya permitiría aunar la actuación de todos los núcleos culturales del exilio.

Ante tal horizonte, aquel grupo de intelectuales cruzó la frontera el día 31 de enero de 1939, llegando a Tolosa del Languedoc el día 3 de febrero y quedando bajo protección del Comité Universitaire Toulousain d'Aide à l'Espagne Republicaine que les procuró su instalación. Otros cruzaron la frontera junto a diferentes unidades militares, con un primer ingreso en diversos campos de concentración creados por las autoridades francesas ante la llegada de los refugiados y antes de alcanzar Tolosa. La actuación desde París por parte de alguno de aquellos escritores ya instalados allí o gracias a relaciones personales, como por parte de Francesc Trabal, en colaboración con un comité de ayuda a los escritores españoles creado por intelectuales franceses, facilitó la instalación de escritores catalanes en dos destinos a pocos kilómetros de París; fueron Roissy-en-Brie y Boissy-la-Rivière a L'IsleAdam, particular entorno de residencias estudiantiles del que saldrían el poemario Elegies de Bierville (1942) de Carles Riba y el doble relato de Anna Murià y Agustí Bartra donde sendos narradores literaturizaron "la nit de vent" en la que indagaron sobre su destino finalmente compartido, desde los iniciales caminos franceses hasta la larga instalación americana (Murià y Bartra 2000). Una y otras son firmas de residentes en aquel inicial destino, nombres y textos junto a los que caben otras tantas rúbricas y relaciones memorialistas que, con el tiempo, recuperarían aquellos 
episodios. Véase el caso de Xavier Benguerel, Memòries. 1905-1940 (1971) y el de Sebastià Gasch, Etapes d'una nova vida: Diari d'un exili (2002). Aún y por último, pensando en fuentes primarias, mencionemos la recuperación de epistolarios, por ejemplo los debidos a escritores, intelectuales y científicos, entre 1939 y 1940, de acuerdo con la recopilación, transcripción y notas de M. Campillo y F. Vilanova (2000). Esta llamada debe hacernos entender que en el material propiamente literario hay una primera fuente de estudio acerca del exilio y de los exiliados.

En cualquier caso, desde esa amplia plataforma de acogida habría de surgir la decisión favorable al establecimiento europeo, pronto sujeto al conflicto bélico continental, o al salto trasatlántico. La evidencia de la aventura americana se constata en los trámites ante los diversos gobiernos tal y como se relata en determinados libros de memorias por parte de sus protagonistas, en ocasiones a través de dos instituciones SERE (Servicio de Evacuación de Republicanos Españoles) y JARE (Junta de Auxilio a los Republicanos Españoles), creadas una por Indalecio Prieto y activada la otra por Juan Negrín a su llegada a Francia. Principales focos de acogida de los expatriados, además de EEUU que tuvo relativa incidencia para los catalanes, acabaron por ser México, Chile, Argentina, Colombia o Cuba. Si bien en alguno de ellos existía una presencia catalana previa debida a la emigración hacia América, su grado de institucionalización a favor de la cultura catalana era limitado. Con una primordial función social, al parecer no cabe comparar su papel con el que, a favor de su cultura de origen, sí operaron los centros fundados por la emigración gallega. En ese entorno, otra generalización acerca de los intelectuales catalanes exiliados en Hispanoamérica: si bien eran competentes en el idioma de las tierras de instalación, el castellano, se hallaron en una geografía lingüísticamente ajena a la lengua de la cultura que habían prometido perpetuar ante la situación desencadenada en España; ese afán les obligaba a mantener un idioma cerrado en el auto-consumo comunicativo y a crear una infraestructura favorable a su crecimiento literario pero ajena a toda posibilidad de mercado que ayudara a su estabilidad. Sólo les cabía, por tanto, el paso a otro sistema cultural y a la vida literaria en otro idioma -práctica que en ocasiones se dio o se compaginó, como medio de subsistencia, con la continuidad en catalán- o el esforzado mantenimiento en la tradición literaria propia y en el idioma catalán. Y aún una última consideración de conjunto ante el exilio catalán, de acuerdo con los compendios de historia de la literatura catalana: si J. Fuster (1978: 325-327) indica que el exiliado catalán no tenía porqué ser necesariamente republicano sino que bastaba con que fuera nacionalista, por ahí se desarmó completamente el espectro cultural propio; ante tal debacle colectiva, tanto J. Fuster como E. Gallén (Molas (dir.) 1987: 214-216, 235-236) perfilan, tras la ocupación alemana de Francia en 1942, un destino preferentemente sudamericano, donde aquella fervorosa actividad comenzó a decaer del año cuarenta y cinco al inicio de los cincuenta, ante el paulatino relanzamiento y publicidad de la voz catalana en la geografía peninsular, en particular a lo largo de esta última década, tiempo en el que se ha considerado que el exiliado fue metamorfoseándose en emigrante; no obstante, coinciden todos los historiadores literarios consultados, aquella extraditada vida literaria fue puente ineludible entre la normalidad de preguerra y la restauración, y, aún más, añade J. Fuster (1978: 327-328), si el exilio en tierras americanas fue el más 
reacio al retorno, allí crecieron literariamente nuevos escritores, en ocasiones abocados al bilingüismo de subsistencia ya mencionado, pero que, en catalán, enriquecieron el imaginario propio con espacios, experiencias y referentes de todo tipo emanados del continente americano. A propósito de las variadas condiciones y circunstancias que incidieron sobre el exilio catalán -entre las ya mencionadas, desde la posible función como espectro receptor de los exiliados por parte de la plataforma socio-cultural surgida de la emigración ochocentista, hasta la revisión de los períodos reconocibles en la perduración de los círculos de exiliados, incluso de la vigencia de sus capitalidades y también del papel ejecutado por los exiliados con respecto a los pasos dados a favor de la normalización cultural catalana en tierra hispana-, atiéndase a la matizada revisión histórica compuesta por J. Molas (1994).

El periplo humano y cultural hasta aquí resumido, cierto es, cuenta hoy con fuentes de conocimiento muy bien documentadas; tanto sobre los primeros pasos de la huida y los iniciales destinos (Rovira i Virgili 1976; Vilanova i Vila-Abadal 2000; Bosch 2000) como acerca de las experiencias relativas a la llegada y a la recepción en tierras americanas (por ejemplo, sobre México: Artís-Gener 1991: III, 20-21; Enríquez Perea 1990; Riera Llorca 1994; Pla Brugat et alii 1997; Pla Brugat 1999; Matesanz 1999; Pla Brugat, 2000; Domínguez Prats 2009). No obstante, en estas premisas y enlazando con una aportación previa sobre los exilios gallego y catalán en Hispanoamérica (Ribera y Mejía 2002), abundaremos en el criterio de que la equiparación de lo hispánico o español con la expresión española en castellano ha ayudado a relegar de los abundantes estudios sobre el exilio español la atención a las otras voces españolas que en vasco, gallego y catalán igualmente nos prueban aquel destino en buena medida compartido. A tal comprensión excluyente de $l o$ español corresponden monografías señeras debidas a Francesc Caudet $(2005,2007)$. Contémplese como, en el caso de referir nombres catalanes, la mención para nada peculiariza cuestiones literariamente catalanas; este es el caso, por ejemplo, de la presencia de José/Josep Carner en las páginas de Caudet (2005: 145, 313, 334; 2007 : 26, 144, 169, 207-208, 258-259, 514, 653).

Aun así, en ese entramado cronológico y bibliográfico, fueron emergiendo criterios de estudio más flexibles; conste en tal dirección el volumen 6 de la obra dirigida por J. L. Abellán (1976), con una aportación conjunta de V. Riera Llorca y A. Manent, o las páginas de El exilio de las Españas de 1939 en las Américas, título coordinado por J. M. Naharro-Calderón (1991), tratando "Los exilios de Catalunya, Galiza y Euskadi". En ese apartado, K. McNerney atiende al crecimiento de la escritura de Anna Murià en y desde las experiencia americana, y J. Ferrán al desarrollo de la alegoría del exilio y del exiliado por parte de Josep Carner con su Nabí (1941), creación poética intuitivamente iniciada el año 1932 en Hendaya, uno de los umbrales de la inmediata deportación, y editada en Buenos Aires (Naharro-Calderón 1991: 285-300).

Desde esta perspectiva de estudio que permitiría cotejar los diversos exilios de cada tradición española en un entramado común, se podría alcanzar aquello que, entre otras finalidades implícitas en este último volumen, se apreciara como "[...] el estudio comparado de los emigrados de todas las Españas", para así entender según qué "aspectos encontrados del exilio español" (Gómez Íñiguez 1992: 335, 337). Ese 
es el aliento que, pensamos, halló su mejor futuro con la creación del Grup d'Estudis de l'Exili Literari (GEXEL), dado a conocer el año 1993 desde la Universitat Autònoma de Barcelona (Dep. de Filologia Espanyola). Dada esta sede y el grupo fundacional del proyecto, cabe entender que la recuperación documental y la lectura crítica del exilio fueran de planteamiento más plural. Auspiciando la convocatoria del Primer Congreso Internacional sobre "El exilio Español de 1939" (1995; ed. actas 1998, vol. I, cap. 10, específico mediante diez aportaciones sobre "Literatura en Lengua Catalana", junto con un Apéndice, vol. II, "Barcelona, memoria del exilio", de Jesús López Pacheco que a todos nos alcanza) y publicaciones como la coordinada por M. Aznar Soler (1999) sobre teatro de la Segunda República y exilio, con un primer bloque de aportaciones sobre teatro y "nacionalidades históricas", todo ello editado por Associació d'Idees / Gexel, ese grupo investigador pasó a convertirse no sólo en un referente, también en eje articulador de un autocalificado como Congreso Plural e itinerante a lo largo de once comunidades autónomas y durante 1999, con la denominación "Sesenta años después" encabezando el título de aquella primera convocatoria. Editados en diferentes fechas, los volúmenes de las sesiones convocadas en la Bellaterra, Tarragona y València (Aznar Soler (ed.) 2000; Mancebo (ed.) 2001) ayudaron a sistematizar la revisión del exilio catalán y a incorporarlo al entramado común con una serie de aportaciones plurales -desde la meditación sobre exilio y literatura hasta un buen número de trabajos específicos sobre autores y textos-, tal como otros volúmenes se habían centrado en documentación castellana, gallega, asturiana o vasca; así mismo, la reunión celebrada bajo auspicio de la estatal UNED parecía marco ideal para contemplar la experiencia plural y quizás por ello cupo alguna llamada en ese sentido (Abellán et alii (dir.) 2003: I, 269280).

Cierto es que, no obstante la urgencia de ese planteamiento plural y la utilidad de los recursos establecidos por GEXEL a favor del estudio específico de cada una de las tradiciones literarias atendidas, incluida la catalana, cabía a cada historiografía literaria la investigación sobre la suerte de la propia tradición y la fortuna de sus creadores ante el abismo histórico en que pudo convertirse el exilio del 39. En nuestro caso, la historiografía literaria catalana hace tiempo indagó en la peripecia de sus letras extrañadas mediante la confección de visiones de conjunto. Con categoría canónica, fue A. Manent quien lanzara la llamada de atención hacia ese capítulo histórico en 1962, favorable a "una recapitulació necesaria" (reed. Manent 1969); desde ese preámbulo su propia labor investigadora progresó hasta su estudio fundamental La literatura catalana a l'exili (1976), que cabe acompañar de las páginas redactadas en colaboración con V. Riera Llorca (Abellán 1976: 157-215), de sus colaboraciones con J. Crexell sobre bibliografía editada en el exilio de 1939 a 1946 (Manent y Crexell 1988: 53-62; 1989: 113-132) y de la aportación "La cultura catalana a l'exili" (Gabriel 1998: 257-272). A propósito del extenso contenido de la indagación de A. Manent que hicimos por sintetizar divulgativamente en su día (Ribera y Mejía 2002: 599-601), destaquemos respecto de la experiencia catalana en Hispanoamérica la relevancia del repertorio de publicaciones periódicas en catalán o bilingües, proyectadas y editadas por el exilio en Argentina, Brasil, Colombia, Cuba, Chile, México, Panamá, República Dominicana, Uruguay, Venezuela y 
EEUU (Manent 1976: 279-287). Quede ese listado como referencia del esfuerzo lingüístico y cultural llevado a cabo en América por los exiliados; valga también como fuente de información a favor de la supervivencia de una tradición literaria entre dos lejanas orillas y como cumplimiento del mencionado compromiso augurado en su día por la Institució de les Lletres Catalanes en el momento de abandonar España. Ante tal capítulo de la historia de la cultura y de las letras, A. Manent (Aznar Soler 1998: 605-612) aún ha aportado un último estado de la cuestión donde, además de citar fuentes aquí soslayadas, calibraba y auguraba lo siguiente:

El conjunto de estudios y memorias sobre el exilio literario catalán ofrece, pues, elementos panorámicos que se completarán con futuros trabajos sectoriales o análisis sobre lo que significó en la diáspora y significó para Cataluña este fenómeno, único en la historia, de una literatura de transterrados que suple a la que estaba rigurosamente prohibida en tierras catalanas. (Aznar Soler 1998: 612)

Sólo cabe añadir que, tanto los volúmenes de GEXEL -véase vaciado de contenidos catalanes en indicaciones bibliográficas- como un buen número de tesis doctorales de los últimos años, han ido atendiendo a esa llamada. Más puntualmente, destáquese el volumen de M. Moguer y C. Guzmán Moncada (2004) quienes, desde la denuncia de "un hispanocentrismo mal disimulado" entre alguna que otra razón de orden historiográfico y de contexto lingüístico-literario, abogan por colaborar en la restauración de la voz catalana emanada desde la otra orilla atlántica: guiados por esa pauta, en primer lugar revisan, introductoria y condensadamente, la trayectoria del desplazamiento de las letras catalanas a tierras americanas; ese estudio actúa a modo de umbral a favor de una Antología, razón fundamental de la obra, que atiende tanto a la producción catalana surgida en México como a la literaturización de cultura y tierra mexicanas por parte de firmas catalanas; y, llegados aquí y mediante meditados criterios de edición que optan por mantener la edición bilingüe de los textos líricos y procurando siempre traducciones de los propios autores o ejecutadas con sumo cuidado, se accede a la selección de textos mexicanos de Josep Carner, Vicenç Riera Llorca, Agustí Bartra, Lluís Ferrán de Pol, Pere Calders, Avel-lí ArtísGener, Ramon Xirau y Manuel Durán. Y aún por informar sobre vías de estudio acerca del exilio español $\mathrm{y}$, en ese marco, del puntualmente catalán, reséñese la fundación de la Asociación para el Estudio de los Exilios y Migraciones Ibéricos Contemporáneos (AEMIC, 1996), grupo investigador vinculado a la UNED. En su publicación Migraciones y Exilios (desde 2000) hallamos, por ejemplo, un volumen monográfico sobre exilio y memoria, con la aportación de T. Fèrriz Roure (2004) acerca de la idea de retorno documentada en revistas catalanas de geografía americana; u otro dedicado a las fuentes archivísticas, con la colaboración sobre materia catalana de F. Vilanova (2007).

Como mención de salida de este primer apartado, recuperemos con brevedad tres ediciones más recientes. Se trata, en primer lugar, de El dia revolt. Literatura catalana de l'exili (2008) de J. Guillamón, cuyo interés por la materia y experiencias vitales aquí revisadas se remonta a unas entrevistas publicadas en el diario Avui a partir de 1986 y cuya primera formulación conjunta se abarca en el catálogo para la 
exposición sobre "Literatures de l'exili" (Guillamón 2005) que viajara desde el CCCB (Centre de Cultura Catalana Contemporània de Barcelona) a sedes de México, Buenos Aires y Chile. El volumen resultante acoge el reencuentro con tantos y tantos testimonios personales del exilio que arropa el cálido soporte fotográfico. Todo, pensamos, bajo el criterio que se expresara en el mencionado catálogo, donde se destaca el "[...] esperit modernitzador, de creativitat, llibertat i progrés" animado por la diáspora española y favorable a sus letras (Cerdeira Monterero en Guillamón 2005: 6). Se apunta, por tanto, hacia una relectura vitalista del exilio que mantuvo y potenció las cuotas de modernidad acotadas entre el cambio de siglos y los años treinta por parte de nuestra intelectualidad. En segundo lugar y debido a J. M. Figueres, Veus de l'exili (2007), volumen que parte del proyecto radiofónico fechado en 2004 a propósito de la recogida del testimonio oral (véase http:/www.catradio.cat/ programa/902/Veus-de-lexili) y que se resuelve mediante un amplio estudio introductorio y una serie de semblanzas de veinte exiliados y exiliadas. La introducción citada incide en la creación de la inmediata plataforma francesa como primer paso de la diáspora, capítulo desde donde muchos de los protagonistas traídos al libro tuvieron que marchar hacia el horizonte americano. En la atención a ese primer episodio francés ha insistido M. Pessarrodona con França 1939. La cultura catalana exiliada (2010), ordenación conjunta y coral de documentación sobre el exilio catalán y acerca de los pasos seguidos hasta la capital francesa. Punto de urgente llegada y de inexorable partida, horizonte que la autora traza, atendiendo entre otros a la gesta de buques como Alsina hacia Argentina, Ipanema rumbo a México o De la Salle dirección República Dominicana, que trasladaron a muchos de los exiliados a tierras de América (Pessarrodona 2010: 329-341).

\section{ESTUDIO Y FUENTES ESPECÍFICAS: UN EXILIADO, AVEL·LI ARTÍS BALAGUER}

Acogiéndonos a la llamada de A. Manent, proponemos como muestra del estadio que él preveía que debiera cubrirse en futuras investigaciones sobre el exilio y los exiliados literarios catalanes, nuestra experiencia investigadora en torno a la figura y a la obra de Avel-lí Artís Balaguer (1881-1954). Escritor que, por los presentes fines, habrá que destacar no sólo como dramaturgo con una obra consolidada desde la década de los años diez, con reconocimiento de crítica y público, sino como editor e impresor, apréciese que fue uno de los intelectuales catalanes que vio truncada su carrera literaria en su geografía cultural y abocado al exilio, con dirección e instalación finalmente mexicana. Pero téngase presente que, y con todo, estas dos últimas vocaciones profesionales fueron sus fuentes de ingresos, a la vez que le permitieron estar en contacto con los distintos puntos del exilio cultural catalán y con el exilio interno de su añorada patria. Ante ese perfil y atendiendo al tipo de fuentes al que hay que recurrir para el conocimiento tanto de la continuidad de su obra como de la suerte de su biografía, ordenamos la siguiente revisión que pudiera servir de muestra de los pasos investigadores que aún cabe dar a la hora de progresar en el estudio de este $\mathrm{u}$ otros exiliados catalanes. 
Uno de los primeros pasos que debe dar el investigador es el de conocer si existió y si se conservó algún tipo de archivo relacionado con él, personal y/o institucional. En muchos de los casos, tendremos la suerte de que haya sido así, a pesar de las peripecias vitales, gracias a la intervención del propio escritor o de algún familiar que pudiera donar su archivo a un fondo como, por ejemplo, el de la BNC. Pero en otras ocasiones todo ese valioso material para conocer no sólo datos biográficos sino también para una mayor comprensión de su obra literaria, se ha perdido por diversas causas. En el caso del intelectual que hemos puesto como ejemplo, parte del material de ese tipo que se generó durante su vida en Barcelona se perdió por la salida precipitada al exilio, así como también el acumulado en México - proyectos, cartas, artículos, toda su rica biblioteca...- se dispersó por disputas familiares tras la muerte de Avel·lí Artís Balaguer, de acuerdo con la relación memorial de su hijo (Artís Gener 1989-1996: III, 275), aunque hay documentación literaria depositada en el fondo del Institut del Teatre (Barcelona). En el caso de nuestro autor, la pérdida mencionada supone, por ejemplo, no poder confirmar la referencia a la escritura de una novela que no llegó a publicarse; por su parte, el IT nos permite recuperar manuscritos de su producción dramática no publicada.

Ante esta dificultad, no hay que obcecarse ya que existen otras posibilidades para ir rellenando esos vacíos. El siguiente paso sería indagar en los diferentes archivos españoles e internacionales, allí donde puedan existir materiales favorables a nuestra investigación. En el tema del exilio a México hay que contar con dos archivos para conocer de cerca la llegada de sus protagonistas, como son los "Fondos del Gobierno de la República en el Exilio", que se encuentran en la Biblioteca del Ministerio de Asuntos Exteriores y Cooperación, y los archivos de "El Comité Técnico de Ayuda a los Republicanos Españoles", conservados en la Biblioteca Nacional de Antropología e Historia de México. Estos dos fondos son complementarios como podremos ver a continuación.

El primer fondo mencionado conserva la documentación que se encontraba en la antigua sede de la Embajada de España en México, enviada una vez se reestablecieron las relaciones diplomáticas entre los dos países en 1977. En él podemos comprobar los datos de aquellos expatriados llegados a Veracruz, puerto de entrada de todos ellos. Si se consultan esos fondos, se accede, de acuerdo con el encabezamiento de los documentos, a "una relación de compatriotas" llegados en los diferentes vapores utilizados en los viajes, como es el Ipanema, barco en el cual llega nuestro intelectual, o, por ejemplo, al conocimiento de los "lugares de residencia en la República mexicana", entre otros contenidos. Por esa vía y sobre Avel·lí Artís Balaguer sabemos algunos datos de su estancia en su primer destino mexicano, Saltillo, donde, como medio de subsistencia, recibe el encargo de publicar un diario que, finalmente, no aparecerá.

Respecto al archivo del CTARE (Ordóñez Alonso 1997), corresponde a toda la documentación generada por el SERE en México. En palabras de José Puche, presidente del organismo, este trabajaba " [...] con [los] medios que iba enviando, en la medida que podía hacerlo, el Gobierno de la República, por medio de don Francisco Méndez Aspe, ministro de Hacienda en ejercicio, que hacia remesas periódicas para atender a esas necesidades, generalmente a través de bancos de México, y que 
yo depositaba en el Banco Nacional de México" (Alonso 1980: 61). Este archivo se conservó gracias al empeño que puso su presidente, quien lo guardó tras la conclusión de la labor de ayuda a los refugiados a mediados de 1940. Primero quedó en su poder y posteriormente, tras su elección como presidente del mejicano Ateneo Español en 1947, fue trasladado allí hasta 1981, fecha en que se entregó a la Biblioteca Nacional de Antropología e Historia del Instituto Nacional de Antropología e Historia de México.

Este fondo mexicano es más detallado en datos para cualquier estudio sobre el exilio que el fondo español mencionado. En él tenemos la referencia de la llegada de unos casi seis mil refugiados a México bajo el amparo del SERE. Los expedientes personales contienen información muy homogénea. Cada expediente constituye el registro de un refugiado "cabeza de familia", pero en ocasiones se abrió uno a cada miembro de cada familia, como es el caso de Avel-lí Artís Balaguer y de sus hijos. En sus documentos y respecto de nuestro autor, nos hemos informado de las condiciones en que llegó a su nuevo destino así como nos confirman que su pareja, la actriz Dolors Peris, no llegó con la familia, según repiten otros estudiosos, sino en un posterior buque.

Para complementar estas dos fuentes de documentación podemos utilizar otros archivos estatales, como los españoles Archivo Histórico Nacional o Archivo General de la Administración. En estos últimos podremos encontrar información sobre los exiliados que tuvieron un papel más activo durante la guerra participando en el frente, o las censuras que sufrieron posteriormente en los intentos de publicar su obra en España. En este caso, nada se nos ofrece sobre Avel-lí Artís Balaguer. Por último, podemos acudir a los archivos personales de los intelectuales que han sido donados a diferentes fondos tras su vuelta a Cataluña; este es el caso del de Artís Gener, cedido a la BNC (Fons Tisner), según queda dicho y que siempre cabrá entender como fuente primaria sobre el exilio de su padre y de la familia Artís, o de los mencionados Agustí Bartra y Anna Murià, depositados en el Arxiu Històric de Terrassa, etc. En todos ellos podemos comprobar, entre otros materiales, la correspondencia entre los diferentes exiliados, fuente que nos informa del entramado existente entre los propios exiliados.

Tras las indagaciones en este tipo de material archivístico, hay que acceder a otras fuentes de información, tan útiles como los documentos oficiales y personales. Nos referimos a las memorias de los exiliados, publicadas a lo largo de estos años aunque editorialmente lanzadas en fechas que cabría entender como tardías. Estas fuentes de información son muy variadas, teniendo que saber valorarlas en la medida justa, conociendo la personalidad de su autor y el aliento de su discurso. Es decir y por ejemplo, las memorias de Artís Gener, Viure i veure (1989-1996), necesariamente complementarias del fondo antes mencionado, son consideradas por sus propios compañeros de generación algo fantasiosas en algunos pasajes; mientras tanto, otras son apreciadas como más verídicas, este sería el caso del volumen mencionado de Xavier Benguerel y de su continuación en Memòries d'un exili: Xile (19401952) (1982).

Otras fuentes importantes son los artículos en prensa y en revistas literarias de y sobre el autor estudiado, tanto del exilio como en geografía catalana. Este material 
nos permite confirmar o ampliar datos que aparecen en las fuentes ya mencionadas. Por ejemplo, hubiera sido muy interesante en nuestro caso la publicación de la proyectada Miscel·lània Artís, tras la muerte de Avel·lí Artís Balaguer, aunque no tenemos constancia de ello. Pero será merced a otra fuente, gracias a la correspondencia conservada por su hijo mayor y que hemos consultado en el citado fondo depositado en la BNC, como sepamos acerca de algunos de los títulos o contenidos de los artículos que debían aparecer en aquella Miscel·lània. Así, en carta del 12 de febrero de 1955 y desde México, Avel-lí Artís Gener expresa a Domènec Guansé la oportunidad de aquel volumen por el número de propuestas que estaba recibiendo sobre los más variados aspectos de la vida de su padre. A partir de esa y de otras cartas, tenemos constancia de colaboraciones como el artículo de Àngel Ferrán en que se evocaría la época de La Publicitat, donde aquel fuera jefe de redacción durante la República y la guerra, o el de Artur Bladé i Desumvila titulado "Els darrers anys d'Avelí Artís", o el de Domènec Guansé quien había pensado redactar "[...] alguna cosa crítica sobre el seu teatre", o el de Rafael Tasis que se titularía "Els anys de La Mainada", otra publicación, infantil en este caso, en la que participaría nuestro autor. De este modo, el recuerdo epistolar de los años de preguerra, manifestado por interlocutores que escriben en posguerra y tras el fallecimiento del autor, se levanta, desde el exilio, como puente entre dos épocas de la cultura catalana. Cuéntese también, en ese sentido, con la serie de artículos "Records de la CIDE" de Artur Bladé i Desumvila en Xaloc, revista del exilio mejicano, donde plasma sus conversaciones con y sus recuerdos de Avel-lí Artís Balaguer, material que posteriormente se convierte en uno de los capítulos del libro De l'exili a Mèxic (1993), siendo este título unas memorias de su exilio.

De este modo es como podemos movernos humana y documentalmente entre los extremos de una biografía que, en la mayoría de los exilios, queda partida. Pensemos que, en el caso de Avel-lí Artís Balaguer, si bien vivió geográficamente tal fractura, culturalmente esa experiencia fue vivida por un intelectual que en los años diez se plantea la renovación de la escena catalana de principios de siglo, cambio que se apreciaba también entre la sociedad y la intelectualidad catalanas (Bladé i Desumvila 1993: 168); y, aún acorde con ese espíritu, en los años cuarenta y desde México, meditaba desde La Nostra Revista (1946-1954), una de las publicaciones que creó en el exilio mexicano, que los problemas de Cataluña debían afrontarse sin melancolía por lo perdido, no cabiendo limitarse a las tradiciones como "[...] ballant sardanes, cantant en un orfeó, llegint l'òrgan de la cleda a la qual està adscrit $\mathrm{i}$ posant-se de tant en tant a la solapa del gec l'ensenya o un bocí de cinta amb les quatre barres" (Artís Gener 1989-1996: III, 268-269).

\section{BIBLIOGRAFÍA}

ABELLÁN, Jose Luis (dir.) (1976): El exilio español de 1939. Madrid: Taurus. (vol 6: V. Riera Llorca y A. Manent, "Literatura catalana en el exilio", pp. 157-215).

ALONSO, María de la Soledad, et al. (1980): Palabras del Exilio I. Contribución a la historia de los refugiados españoles en México. México: INAH Librería Madero. 
ARTÍS-GENER, Avel-lí (1989-1996): Viure i veure. Barcelona: Pòrtic.

ARXIU HISTÒRIC DE TERRASSA, Fons A. Bartra y A. Murià: Arxiu municipal de Terrasa [en línea]. Disponible en: http://arxiumunicipal.terrassa.cat

AZNAR SOLER, Manuel (dir.) (1999): El exilio teatral republicano de 1939. Sant Cugat del Vallès: Associació d'Idees / GEXEL (J. Aulet, "El teatro en lengua catalana y el exilio de 1939", pp. 119-134).

- (ed.) (1998): El exilio literario español de 1939. Sant Cugat del Vallès: Associació d'Idees / GEXEL (vol. I: J. Arevalo i Cortès, "Quaranta anys a la sala d'espera: l'exili voluntari de Lluís Capdevila"; J. Aulet, "La correspondencia d'exili d'Agustí Bartra"; Ll. Busquets i Grabulosa, "Epistolaris de Xavier Benguerel: un pou d'informacions"; M. Campillo, "El grup d'exiliats catalans a Roissy-en-Brie"; N. Carbonell, "Exilio, escritura y el género fantástico en los cuentos de Mercè Rodoreda"; J. Espinós i Felipe, "Erem quatre de Lluís Ferran de Pol: entre el mite i la música"; J. Ferran Camps, "Els exilis de Josep Carner"; A. Manent, "Estado de la cuestión: el exilio literario catalán (estudios y memorias)"; J. Melcion, "Mèxic en la literatura de Pere Calders"; F. Vilanova i VilaAbadal, "Carles Pi i Sunyer i la cultura catalana a l'exili", pp. 527-629).

- (ed.) (2000): Las literaturas del exilio republicano de 1939. Sant Cugat del Vallès: Associació d'Idees / GEXEL (vol. I: J Castellanos, "L'exili literari català: continuïtat i ruptura”, pp. 31-44; J. Domingo, "El valenciano Manuel Uribarri y su exilio en Cuba”, pp. 5364; E. Esteve Latorre, "Josep Carner Ribalta: dos exilis i una execpció", pp. 65-69; A. Manent, "El salvament i el traspàs del cardenal Vidal i Barraquer", pp. 71-80; J. Massot i Muntaner, "El primer exili d'Antoni M. Sbert", pp. 81-95; L1. Meseguer, "Exili, política i comunicació literària (reflexió provisional sobre l'obra de Diego Perona)" pp. 105118; F. Vilanova i Vila-Abadal, "Política i cultura en el primer exili", pp. 119-127; J.-V. Garcia i Raffi, "La memòria literària del camp de concentració de Saint-Cyprien: de Lluís Ferran de Pol a Manuel Andujar", pp. 141-152; X. Gaspar i Blancafort, "Dues memòries sobre l'èxode cátala", pp. 153-160; J. Arévalo, "Presència i pervivència a la revista Catalunya de Buenos Aires de la tradició barcelonina més significativa de la cultura de masses de preguerra", pp. 173-185; T. Férriz Roure, "La conformació d'un discurs identitari a les revistes culturals catalanes de Mèxic", pp. 187-195; C. Bastons i Vivanco, "La reversibilitat de la relació Max Aub-Catalunya, amb l'exili com a rerafons", pp. 317-326; M. J. Gallofré Virgili, "Exili i retorn”, pp. 353-359; J. Laguna, "Tras los pasos de Abelard en el epistolario entre Rafael Tasis y Lluís Nicolau d'Olwer", pp. 361-370; L. Monferrer, "Domènec Perramon en la BBC", pp. 385-397; J. Romaguera i Ramiò, "Literatura Audiovisual (cinema, televisió) d'exiliats del 1939 dels Països Catalans a les Amèriques", pp. 407-416; J. Aulet, “Algunes dades sobre la recepció de l'obra d'Agustí Bartra durant els anys de l'exili", pp. 419-437; M. Campillo, "De la ventura en la poesia de l'exili", pp. 459-469; M. Durán, "Ters grans escriptors catalans a Mèxic: Josep Carner, Agustí Bartra i Pere Calders", pp. 471-484; J. Ferran, "Les Elegies de Bierville, summa de l'exili", pp. 485-489. Vol. II: E. Balaguer, "Mèxic i el tema de l'autodestrucció: Sota el volcà (1947) de Malcolm Lowry i Naufragis (1956) de Ferran de Pol", pp. 173-183; M. Bertrand de Muñoz, "Narradoras españolas en el exilio", pp. 203214; G. Casals, "Algunes qüestions (sense resoldre) sobre la gènesi i el gènere de Tots tres surten per l'Ozama, de Vicenç Riera Llorca", pp. 215-222; C. Cortés i Orts, "El tractament de la realitat en els contes de l'exili (Xavier Benguerel i Mercè Rodoreda)", pp. 223-239; J. Espinós Felipe, "Tranculturació i exili”, pp. 251-259; O. Ferran, “Encontrarse con las manos vacías': el desarraigo en la escritura del exilio de Mercè Rodoreda”, pp. 273-284; S. Mas, "La qüestió dels gèneres en 556 Brigada mixta, d'Avel·lí Artis Gener”, pp. 381-392; F. X. Vall i Solaz, “L'existencialisme en l'obra d'Humbert Parde- 
llans”, pp. 491-508; L. Domergue, "Josep Ferrer Aymar y el teatro del Casal Català de Toulouse (1944-1978)", pp. 545-558; M. Gustà, "De dèus i de prínceps. Sobre el sentit d'El Ben Cofat i l'Altre de Josep Carner", pp. 559-566; C. Fontserè, "El cap de concentració de Saint-Cyprien”, pp. 601-614; M. Soler, “J. Soler Vidal”, pp. 647-650).

BIBLIOTECA NACIONAL DE CATALUNYA (BNC) - Fons Tisner [en línea]. Disponible en: http://www.bnc.es/fons/inventaris/tisner.pdf

BLADÉ I DESUMVILA, Artur (1993): De l'exili a Mèxic. Barcelona: Curial.

BOSCH, Maria Àngels (2000): "París 1940. Pous i Pagès i Lluís Companys". Serra d'Or, núm. 485, pp. 43-47.

CAMPILLO, Maria; y VILANOVA, Francesc (2000): La cultura catalana en el primer exili, 1939-1940: cartes d'escriptors, intel-lectuals i científics. Barcelona: Fundació Carles Pi i Sunyer d'Estudis Autonòmics i Locals.

CATALUNYA RADIO: Veus de l'exili [en línea]. Disponible en: http:/www.catradio.cat/ programa/902/Veus-de-lexili

CAUDET, Francesc (2005): El exilio republicano de 1939. Madrid: Cátedra.

- (2007): El exilio republicano en México. Las revistas literarias (1939-1971). Alicante: Publicaciones de la Universidad de Alicante.

DOMÍNGUEZ PRATS, Pilar (2009): De ciudadanas a exiliadas: un estudio sobre las republicanas españolas en México. Madrid: Cinca.

ENRÍQUEZ PEREA, Alberto (1990): México y España: solidaridad y asilo político (19361942). México: Secretaría de Relaciones Exteriores.

FÈRRIZ ROURE, Teresa (2004): "Las miradas del retorno" Migraciones y Exilios, núm. 5, pp. 51-62.

FIGUERES, Josep Maria (2007): Veus de l'exili. 20 testimonis de la diàspora catalana. Valls: Cossetània Edicions.

FUSTER, Joan (1978): Literatura catalana contemporània. Barcelona: Curial.

GABRIEL, Pere (dir.) (1998): Història de la cultura catalana. Barcelona: Edicions 62. (vol. 10: A. Manent, "La cultura catalana a l'exili", pp. 257-272).

GÓMEZ ÍÑIGUEZ, Laura (1992): "Naharro-Calderón, José María (coord.): El exilio de las Españas de 1939 en las Américas: ‘A dónde fue la canción?’”. Barcelona: Anthropos, 1991”. Revista de Filología Románica, núm. 9, pp. 335-338.

GRUP D'ESTUDIS DE L'EXILI LITERARI (GEXEL): http://www.gexel.es.historialgrupo.html.

GUILLAMÓN, Julià (2005): Literatures de l'exili. Barcelona: Diputació de Barcelona / CCCB.

- (2008): El dia revolt. Literatura catalana de l'exili. Barcelona: Empúries.

INSTITUT DEL TEATRE (IT): http://www.institutdelteatre.org/

INSTITUTO NACIONAL DE ANTROPOLOGÍA E HISTORIA, Fondo CTARE: http://www.gobiernodigital.inah.gob.mx/mener/index.php?contentPagina=19

MANCEBO, María Fernanda; BALDÓ, Marc; y ALONSO, Cecilio (eds.) (2001): L'exili cultural de 1939. Valencia: Universidad de Valencia / Biblioteca Valenciana (vol. II: M. Bertrand de Muñoz, "Xavier Benguerel. La guerra civil y el retorno", pp. 281-288; M. J. Sigalat Vayá, "La recuperació de l'arxiu personal i de funció de Julio Just (Alborai València) com a font d'investigació històrica", pp. 551-559).

MANENT, Albert (1969): Literatura catalana en debat. Barcelona: Curial.

- (1976): La literatura catalana a l'exili. Barcelona: Curial.

MANENT, Albert; y CREXELL, Joan (1988): Bibliografia catalana dels anys més difícils (1939-1943). Barcelona: PAM.

- (1989): Bibliografía catalana cap a la represa (1944-1946). Barcelona: PAM. 
MATESANZ, José Antonio (1999): Las raíces del exilio. México ante la guerra civil española. México: Colegio de México / Universidad Nacional Autónoma de México.

MINISTERIO DE ASUNTOS EXTERIORES Y COOPERACIÓN (MAEC, Breve descripción de Fondos): Fondos del Gobierno de la República en el Exilio (1939-1954). En: http://www.maec.es/es/MenuPpal/Actualidad/Documentacion/Paginas/ArchivosBibliotecasyCentrosdeDocumentacion.aspx

MOLAS, Joaquim (1994): "Otra literatura iberoamericana. Notas sobre la aventura de la literatura catalana en tierras de América", en Actas del XXIX Congreso del Instituto Internacional de Literatura Iberoamericana, vol I, pp. 49-66. Barcelona: PPU.

- (dir.) (1987): Història de la literatura catalana. Barcelona: Ariel (vol. 10: E. Gallén, "La literatura sota el franquisme: de l'ostracisme a la represa pública", pp. 213.241).

MURIÀ, Anna; y BARTRA, Agustí (2000): Dos contes autobiogràfics A cura de J. Arlet. Terrassa: Ajuntament de Terrassa.

NAHARRO-CALDERÓN, Jose María (coord.) (1991): El exilio de las Españas de 1939 en las Américas: “A dónde fue la canción?”. Barcelona: Anthropos (K. McNerney, "Catalanes exiliados en México: Anna Murià y Agustí Bartra”; J. Ferrán, "Josep Carner en Nabî', pp. 285-300).

NOGUER FERRER, Marta: y GUZMÁN MONCADA, Carlos (comp.) (2004): Una voz entre las otras. México y la literatura catalana del exilio. Selección, traducción, estudio preliminar y notas de M. Moguer y C. Guzmán: México D. F.: Fondo de Cultura Económica.

ORDÓÑEZ ALONSO, María Magdalena (1997): El Comité Técnico de Ayuda a los Republicanos Españoles: historia y documentos, 1939-1940. México: Instituto Nacional de Antropología e Historia.

PESSARRODONA, Marta (2010): França 1939. La cultura catalana exiliada. Badalona: Ara Llibres.

PLA BRUGAT, Dolores (1999): Els exiliats catalans. Un estudio de la emigración republicana española en México. México: Instituto Nacional de Antropología e Historia / Orfeó Català de Mèxic.

- (2000): Els exiliats catalans a Mèxic: un estudi de la immigració republicana. Catarroja / Barcelona: Afers.

PLA BRUGAT, Dolores; ORDOÑEZ, María Magdalena; y FÈRRIZ ROURE, Teresa (1997): El exilio catalán en México. Notas para su estudio. México: Colegio de Jalisco / Generalitat de Catalunya.

RIBERA, Juan M.; y MEJÍA, Carmen (2002): “El exilio gallego y catalán en Hispanoamérica: aproximación a las fuentes bibliográficas para su estudio", en Romanische Sprachen in Amerika. Festchrift für H.-D. Paufler zum 65. Geburtstag, K. Störl \& J. Klare, pp. 593-601. Frankfurt am Main: Peter Lang.

RIERA LLORCA, Vincenç (1994): Els exiliats catalans a Mèxic. Barcelona: Curial.

ROVIRA I VIRGILI, Antoni (1976): Els darrers dies de la Catalunya republicana. Memòries sobre l'èxode catalá. Barcelona: Curial.

VILANOVA I VILA-ABADAL, Francesc (2000): "Política i cultura en el primer exili", en Sesenta años después. Las literaturas del exilio republicano de 1939, vol. I, pp. 119-127. Sant Cugat del Vallès: Associació d'Idees / Gexel.

VILANOVA, Francesc (2007): "Fuentes para el estudio del exilio catalán. Un balance provisional y parcial”. Migraciones y Exilios, núm. 8, pp. 137-148. 